\title{
GEOCONSERVAÇÃO DA FORMAÇÃO PIMENTEIRA (DEVONIANO, NE BRASIL) POR MEIO DE COLEÇÕES PALEONTOLÓGICAS: A RELEVÂNCIA DO \\ PATRIMÔNIO GEOLÓGICO EX SITU
}

GEOCONSERVATION OF THE PIMENTEIRA FORMATION (DEVONIAN, NE BRASIL) THROUGH PALEONTOLOGICAL COLLECTIONS: THE RELEVANCE OF EX SITU GEOLOGICAL HERITAGE

\author{
CARLA MEDEIROS SOLIDADE DOS SANTOS ${ }^{1}$, JOÃO MARCELO PAIS DE REZENDE ${ }^{2,3}$, LUIZA CORRAL MARTINS DE \\ OLIVEIRA PONCIANO ${ }^{1,3}$
}

\begin{abstract}
1 Universidade Federal do Estado do Rio de Janeiro - UFRJ, Centro de Ciências Biológicas e da Saúde. Avenida Pasteur de 351/352 ao fim, Urca, 22290255 - Rio de Janeiro, RJ - Brasil. E-mail: carla.solidade@gmail.com

2 Universidade do Estado do Rio de Janeiro - UERJ, Programa de Pós Graduação em Ecologia e Evolução. Rua São Francisco Xavier, 524- sl 224, Pavilhão Haroldo Lisboa da Cunha, Maracanã, 20550-019 - Rio de Janeiro - RJ. E-mail: jmprezende@edu.unirio.br 3 Universidade Federal do Estado do Rio de Janeiro - UNIRIO, Laboratório de Tafonomia e Paleoecologia Aplicadas - LABTAPHO. Avenida Pasteur 458, sala 504, Urca, 22290255 - Rio de Janeiro, RJ - Brasil. E-mail: luiza.ponciano@unirio.br
\end{abstract}

Resumo - Coleções paleontológicas são os principais representantes do chamado Patrimônio Geológico ex situ. Com a degradação de afloramentos fossilíferos e sua consequente perda de informações, como ocorre na Formação Pimenteira, as coleções se tornam providenciais para a continuidade das pesquisas. Assim, foi feito um resgate do conteúdo ex situ da Formação Pimenteira, resultando em ao menos 54 fontes bibliográficas e 1.639 números de tombo, distribuídos entre quatro coleções visitadas e cinco analisadas por bibliografia. Foram contabilizados 1.871 espécimes, distribuídos em sete grupos invertebrados, três vertebrados, dois vegetais e icnofósseis. Foram exemplificadas também interrelações entre os materiais que compõe o Patrimônio Geológico ex situ.

Palavras-chave: Coleções científicas; Formação Pimenteira; Fósseis; Patrimônio Geológico.

Abstract - Paleontological collections are the main representant of the ex situ Geological Heritage. With the destruction of geopaleontological outcrops and its following loss of information, as it happens in the Pimenteira Formation, the collections become providential for new studies. Therefore, this paper made a rescue of the Pimenteira Formation ex situ content, resulting in at least 54 bibliographical references and 1.639 numbers of registration distributed among four visited collections and five analyzed by bibliography. Were also identified 1.871 specimens, distributed among seven invertebrate groups, three vertebrates, two plants and icnofossils. Were also exemplified interrelations between the materials that composes the ex situ Geological Heritage.

Keywords: Fossils; Geological Heritage; Pimenteira Formation; Scientific Collections.

Citação: SANTOS, C. M. S; RESENDE, J. M. P. PONCIANO, L. C. M. O. 2021. Geoconservação da Formação Pimenteira (Devoniano, NE Brasil) por meio de coleções paleontológicas: a relevância do patrimônio geológico ex situ. Boletim Paranaense de Geociências, 79 : 60-81. URL: http://bpgbrasil.com.br/ 


\section{INTRODUZINDO O CONCEITO DE PATRIMÔNIO GEOLÓGICO}

Uma das grandes ameaças atuais ao avanço dos estudos paleontológicos é a recorrente destruição de afloramentos fossilíferos e, junto com eles, todas as informações geológicas preservadas ao longo de milhares de anos. Apesar da degradação de afloramentos geológicos ser um processo natural, muitos são os fatores que podem levar à degradação acelerada, principalmente pela exploração destas rochas sedimentares e sedimentos como recursos minerais ou sua descaracterização decorrente do crescimento demográfico, com a construção de casas e estradas. $\mathrm{Na}$ tentativa de conter este processo de destruição intensiva da geodiversidade, foi criado o conceito de Patrimônio Geológico que, junto aos esforços de proteção da biodiversidade, formam o Patrimônio Natural (Ponciano et al. 2011; Silva et al. 2020).

O termo geodiversidade foi cunhado pela primeira vez em 1940, pelo geógrafo argentino Frederico Alberto Daus, que o empregou como um sinônimo de diversidade geográfica, representada, em sua visão, pelo conjunto de representações socioculturais e pelos aspectos naturais da paisagem (Meira \& Morais 2016). Ao longo dos anos, o significado do termo geodiversidade se modificou acompanhando a crescente visão ambientalista e culminando na sua definição básica atual. Hoje, o termo geodiversidade se restringe apenas a parte abiótica da paisagem, sendo definido ainda na década de 1990 pela Royal Society for Nature Conservation do Reino Unido como: "variedade de ambientes geológicos, fenômenos e processos ativos que dão origem a paisagens, rochas, minerais, fósseis, solos e outros depósitos superficiais que são suporte para a vida na terra" (Brilha 2005). Posteriormente, Gray (2013) concorda com a definição apresentada anteriormente, especificando e citando exemplares da diversidade geológica, e definindo-a como diversidade geológica natural de rochas, minerais, fósseis, processos geomorfológicos ligados ao relevo e topografia, assim como aspectos ligados a hidrologia e a água. Incluindo todas as associações, estruturas, sistemas e contribuições à formação do relevo.

O conceito de Patrimônio Natural foi definido pela Convenção para a Proteção do Patrimônio Mundial, Cultural e Natural, adotada pela UNESCO em 1972 durante a Conferência Geral, realizada em Paris (https://whc.unesco.org/archive/conventionpt.pdf). Apesar das formações geológicas estarem inclusas nesta definição inicial, diversos autores concluíram a necessidade de focar esforços mais diretamente nos aspectos geológicos do ambiente, de onde surgiu o Patrimônio Geológico. Um dos principais marcos destes esforços para a proteção do Patrimônio Geológico foi a "Declaração Internacional dos Direitos à Memória da Terra", editada em 1991 durante o I Simpósio Internacional sobre a Proteção do Patrimônio Geológico, ocorrido na comuna francesa Digne Les Bains (Machado \& Ruchkys 2015).

O Patrimônio Geológico, não é considerado sinônimo, mas se refere à parte da geodiversidade que possui algum valor atribuído, seja por sua raridade ou outro aspecto que o diferencie. Esta delimitação foi discutida por diversos autores (e.g. Silva \& Nascimento 2016; Castro et al. 2018; Kunzler \& Machado 2019), sendo algumas das definições correntes:

"Por Patrimônio Geológico se pode entender todas aquelas formações rochosas, estruturas, acumulações sedimentares, formas, paisagens, depósitos minerais ou paleontológicos, ou coleções de objetos geológicos de valor científico, cultural ou educativo e/ou de interesse paisagístico ou recreativo. Também podem ser incluídos elementos de arqueologia industrial relacionados com instalações de exploração de recursos geológicos" (Traduzido de UCEDA 1996).

"Conjunto de geossítios (ou locais de interesse geológico) inventariados e 
caracterizados de uma dada região, sendo os geossítios locais bem delimitados geograficamente, onde ocorrem um ou mais elementos da geodiversidade com singular valor do ponto de vista científico, pedagógico, cultural turístico ou outro" (Brilha 2005).

"Todos os recursos naturais não renováveis de valor científico, cultural, educativo e/ou de interesse paisagístico e recreativo, quer sejam formações rochosas, estruturas geoformas, acumulações sedimentares, ocorrências minerais, paleontológicas ou outras que permitam reconhecer, estudar e interpretar a evolução da história geológica da Terra e os processos que a têm modelado" (Machado \& Ruchkys 2015).

"Patrimônio Geológico se refere à (i) ocorrências in situ de elementos de geodiversidade de alto valor científico geossítios e (ii) elementos de geodiversidade ex situ que, apesar de removidos de seu local natural de origem, mantém alto valor científico (por exemplo, minerais, fósseis e rochas disponíveis para pesquisa em coleções de museus)" (Traduzido de Brilha, 2016).

Apesar de alguns autores não reconhecerem a geodiversidade ex situ como Patrimônio Geológico, reconhecendo apenas seus valores, autores como Ponciano et al. (2011), Mansur et al. (2013), Brilha (2016), Castro et al. (2018) e Silva et al. (2020) discutiram a necessidade de incluir nas definições propostas o conteúdo geológico retirado de seu sítio de origem, além de outros elementos pertinentes, adotando a seguinte definição que inclui: "coleções de objetos geológicos de valor científico, cultural ou educativo e/ou de interesse paisagístico ou recreativo" (Uceda 1996 apud Ponciano et al. 2011). Sendo essa visão também adotada pela presente pesquisa. A inclusão de "objetos geológicos" permite que a definição de Patrimônio Geológico possa englobar o conteúdo geológico salvaguardado em acervos científicos, ampliando a importância também destes objetos para a conservação do ambiente. Partindo desta adição, Ponciano et al. (2011) propôs então a seguinte divisão:
Patrimônio Geológico in situ: corresponde ao conjunto de depósitos minerais ou fossilíferos (aflorantes ou não), paisagens e solos de determinada região, bem delimitados geograficamente, onde ocorrem elementos da geodiversidade com singular valor do ponto de vista científico, didático, cultural, estético, entre outros.

Patrimônio Geológico ex situ: os exemplares da geodiversidade retirados do seu sítio de origem para integrarem coleções científicas de instituições de pesquisa e os registros relacionados à coleta, acondicionamento e estudo deste material e de outros elementos da geodiversidade que apresentem conspícuo valor científico, didático, cultural, estético, entre outros. Os autores exemplificam como parte deste patrimônio, coleções científicas de instituições de pesquisa (museus e universidades, entre outros), publicações científicas físicas ou digitais, além de dados científicos não publicados (monografias, dissertações, teses, cadernetas de campo, fotografias, filmes, ilustrações, mapas, perfis estratigráficos,...). Também são incluídos diferentes tipos de reproduções tais como réplicas de fósseis, rochas e minerais e as reconstituições anatômicas, biomecânicas, paleoambientais, paleoecológicas e paleogeográficas vigentes em época pretérita e significativas para metodologia então utilizada, além de instrumentos científicos e laboratórios antigos utilizados no desenvolvimento de estudos geológicos, paleontológicos ou em áreas relacionadas.

Ambos os tipos de Patrimônio Geológico são de extrema importância para a continuidade dos estudos paleontológicos, contudo, o estudo do Patrimônio Geológico ex situ contido em acervos compreende algumas particularidades. De acordo com Kunzler et al. (2014) todo acervo científico tem como função básica catalogar exemplares, com intuito principal de preservar o conhecimento e permitir o estudo continuado através de diferentes pesquisadores. Contudo, um acervo científico também assume um conjunto de significados científico, histórico e 
cultural assumidos ao longo do seu desenvolvimento.

Essa noção se amplia quando voltada às coleções paleontológicas, uma vez que um fóssil é, por definição, um registro da evolução da vida e dos ambientes naturais ao longo do tempo geológico. Ao tornar-se parte de uma coleção, o fóssil não se torna apenas um registro geobiológico, mas também um registro histórico da coleção e instituições na qual foi depositado, além da história dos pesquisadores que o coletaram e estudaram (Kunzler et al. 2014). Para além destas definições, um acervo fossilífero tem importância também para a prática do "fazer paleontologia", evitando retornos excessivos ao local estudado, uma movimentação muitas vezes dispendiosa considerando transporte, dificuldades de acesso à região e os custos do trabalho de campo em si, podendo levar à uma extração excessiva, descaracterizando o Patrimônio Geológico in situ (Ponciano et al. 2012a; Machado et al. 2017). A situação recorrente de cortes de verba à ciência no país e a necessidade cada vez maior de construir o saber científico de forma integrada, torna o uso de forma mais consistente dos materiais ex situ ainda mais determinante para o preenchimento de lacunas referentes ao conhecimento geopaleontológico.

Partindo da necessidade de fortalecer a conservação do Patrimônio Geológico brasileiro, diversas propostas no âmbito do Patrimônio Geológico in situ têm sido formalizadas por meio de um processo mediado pela Comissão Brasileira de Sítios Geológicos e Paleobiológicos - SIGEP, criada em 1997 (Meira \& Morais 2016). Hoje, são mais de 100 sítios geológicos formalizados, porém muitas regiões de interesse ainda precisam receber estratégias de conservação. No caso da Formação Pimenteira, apenas o afloramento Oiti (sítio 051) foi oficialmente catalogado. A conscientização sobre a importância do Patrimônio Geológico ex situ para a conservação se encontra em um estágio inicial, necessitando maior atenção dos pesquisadores para além dos dados quantitativos, em face de todo o conteúdo acumulado nos anos de pesquisa.

Os afloramentos da Formação Pimenteira se encontram distribuídos ao longo de todo o Piauí, com maior concentração na região central, e nos entornos da cidade de Palmas, capital do Tocantins. Muitos de seus afloramentos já apresentam estado avançado de degradação antrópica decorrentes, principalmente, do crescimento desordenado das cidades de Picos e Pimenteiras, no estado do Piauí. O crescimento urbano chegou a tornar inacessíveis muitos afloramentos fossilíferos, a exemplo do Morro do Cemitério, hoje, com diversas habitações (Ponciano et al. 2012a). A impossibilidade de acessar parte dos afloramentos da Formação Pimenteira demonstra a necessidade de retomar o foco para as coleções paleontológicas, que salvaguardam inclusive material da referida localidade. Assim, o Patrimônio Geológico ex situ se mostra providencial para a continuidade dos estudos geopaleontológicos da região.

Partindo dessa problemática e da necessidade de salientar o papel que as coleções paleontológicas exercem na proteção das informações geopaleontológicas, foi feito um resgate do conteúdo ex situ da Formação Pimenteira por meio de algumas das principais coleções paleontológicas do Rio de Janeiro, além de outras instituições que foram relevantes ao longo dos anos para o seu estudo. Além de explicitar a riqueza do material fossilífero disponível para pesquisa nestas instituições, este trabalho se propõe a exemplificar as possibilidades e interrelações dos diferentes materiais que constituem o Patrimônio Geológico ex situ.

\section{ASPECTOS GEOLÓGICOS REGIONAIS}

A região de estudo se encontra nos estados do Piauí e Tocantins, que compõem parte da Bacia do Parnaíba, uma bacia intracratônica de aproximadamente $600 \mathrm{mil} \mathrm{Km}^{2}$. 
Divide-se em seis sequências estratigráficas, sendo a sequência mesodevonianaeocarbonífera correspondente ao intervalo Devoniano, por sua vez dividida nas formações Jaicós, Itaim, Pimenteira, Cabeças e Longá (Vaz et al. 2007).

Dentre as formações mencionadas, aquela que será aqui estudada na presente pesquisa será a Formação Pimenteira, unidade geológica dividida em duas subunidades, Membro Picos (basal) e Membro Passagem (superior), datada do Devoniano Médio ao Devoniano Superior (Ponciano 2013). O termo "Pimenteira" foi cunhado por Small (1914), e faz alusão à espessa camada de folhelhos localizada próximo ao atual município de Pimenteiras, no estado do Piauí. Esta formação marca o primeiro grande momento transgressivo do Devoniano da Bacia do Parnaíba, que se inicia no Eifeliano, atingindo seu máximo no início do Givetiano (Melo 1988)

O Membro Picos é composto predominantemente por arenitos finos com estratificações cruzadas hummocky intercalados com folhelhos bioturbados e siltitos com estratificações plano-paralelas (Ponciano, 2012). O Membro Passagem, por sua vez, é composto por arenitos finos, muito micáceos, com estratificações cruzadas hummocky e assintótica, arenitos e siltitos com laminação paralela (Ponciano, 2012). Ao contrário do Membro Picos, o Membro Passagem somente é encontrado nos afloramentos da margem leste da bacia, no estado do Piauí. De acordo com interpretações de Ponciano \& Della Fávera (2009) e Ponciano et al. (2012b), o Membro Passagem corresponde a porção distal da barra de desembocadura de deltas dominados por inundações. É considerado um paleoambiente marinho raso, porém de inundações fluviais episódicas.

\section{MÉTODOS DE ESTUDO}

O material foi reunido mediante consulta à bibliografia e aos catálogos das coleções paleontológicas estudadas. Foram visitadas as seguintes coleções: "Fósseis Paleozoicos da UNIRIO" do Laboratório de Estudo de Comunidades Paleozoicas (LECP/UNIRIO), as coleções do Museu Nacional (MN/UFRJ), do Instituto de Geociências (IGEO/UFRJ) e do Museu de Ciências da Terra (MCTer/CPRM/RJ). Também foram reunidas, apenas por meio de bibliografia, informações das coleções do Laboratório de Paleobiologia da Universidade Federal do Tocantins (UFT), do Museu de Geociências da Universidade de Brasília (UnB), do Departamento de Geologia da Universidade Federal do Pernambuco (UFPE), do Museu Paraense Emílio Goeldi (MPEG), além das coleções americanas do Cincinnati Museum Center (CMC). O histórico geral dos acervos foi reconstituído principalmente devido à páginas online disponibilizadas pelas instituições analisadas.

\section{UMA VISÃO GERAL DAS COLEÇÕES DA FORMAÇÃO PIMENTEIRA}

As coleções estudadas somam 1.340 números de tombo contendo exemplares da Formação Pimenteira e, em adição a este material, puderam ser identificados 299 números por meio da bibliografia disponível. Portanto, foi localizado um total de 1.639 números de tombo que integram o Patrimônio ex situ da Formação Pimenteira (Tabela 1). Apesar de não representar sua totalidade, com base nos dados obtidos a partir de toda a bibliografia consultada (e mencionada no próximo tópico: resumos, artigos, monografias, dissertações, teses), podemos evidenciar que este material fornece uma ampla gama de possibilidades, desde estudos mais tradicionais dentro da paleontologia, passando pelo enfoque patrimonial, até mesmo estudos socioambientais, culturais e didáticos. A Formação Pimenteira tem grande importância no que se refere à pesquisa científica, 
contudo, o crecimento de edificações em regiões como os municípios Picos, Pimenteiras e arredores tem levado a constante degradação dos afloramentos e consequente perda do patrimônio paleontológico (Ponciano et al., 2012a).

Os registros encontrados mostraram que a paleofauna da Formação Pimenteira era formada por pelo menos 12 grupos taxonômicos distintos: braquiópodes (Filo Brachiopoda), biválvios (Classe Bivalvia), gastrópodes, dentre os quais belerofontídeos (Classe Gastropoda), tentaculitoides (Classe Tentaculitoidea), trilobitas (Classe Trilobita), conularídeos (Família Conulariidae), crinoides (Classe Crinoidea) e restos fósseis de peixes (Classes Placodermi, Chondrichthyes e Acanthodii), além de registros de restos de vegetais terrestres (Filos Lycopodiophyta e Pteridophyta) carreados para o ambiente marinho durante o período de deposição da formação, além de grande quantidade de icnofósseis.

Pelo fato de muitos números de tombo estarem associados a mais de um grupo taxonômico e, portanto, serem contabilizados mais de uma vez para a análise quantitativa, os valores totais de números de tombo nas coleções e por grupos encontrados divergem. Foram contabilizados 1.883 registros distribuídos entre os diferentes grupos taxonômicos (Tabela 2).

Tabela 1. Quantidade de números de tombo encontrados por coleção, membros da Formação Pimenteira e total analisado.

\begin{tabular}{lccc}
\hline Instituições & Mb. Picos & Mb. Passagem & Total \\
\hline UNIRIO & 234 & 293 & 527 \\
\hline IGEO & 472 & 95 & 567 \\
\hline UFPE & 18 & $x$ & 18 \\
\hline CMC & 63 & 20 & 83 \\
\hline MCTer & 63 & 48 & 111 \\
\hline MN & 36 & 99 & 1354 \\
\hline MPEG & 47 & 9 & 56 \\
\hline UnB & 87 & $x$ & 87 \\
\hline UFT & 54 & $x$ & 54 \\
\hline AMNH & $x$ & 1 & 1 \\
\hline Total & 1074 & 565 & 1639 \\
\hline
\end{tabular}

Tabela 2. Quantidade de espécimes por grupo fóssil, coleção e total analisado.

\begin{tabular}{lcccccccccccc}
\hline Fósseis & LECP & IGEO & MN & MCTER & CMC & AMNH & MPEG & UFPE & UnB & UFT & Total \\
\hline Conularídeo & $\mathrm{x}$ & 1 & 1 & 1 & 2 & $\mathrm{x}$ & $\mathrm{x}$ & $\mathrm{x}$ & $\mathrm{x}$ & $\mathrm{x}$ & 5 \\
\hline Braquiópode & 197 & 95 & 141 & 59 & 14 & $\mathrm{x}$ & 4 & $\mathrm{x}$ & 70 & 5 & 585 \\
\hline Bivalvio & 93 & 164 & 12 & 17 & 13 & $\mathrm{x}$ & 56 & $\mathrm{x}$ & $\mathrm{x}$ & $\mathrm{x}$ & 207 \\
\hline Gastrópode & 173 & 1 & 6 & 6 & 5 & $\mathrm{x}$ & $\mathrm{x}$ & $\mathrm{x}$ & $\mathrm{x}$ & $\mathrm{x}$ & 191 \\
\hline Tentaculitoideo & 33 & 3 & $\mathrm{x}$ & 3 & $\mathrm{x}$ & $\mathrm{x}$ & $\mathrm{x}$ & $\mathrm{x}$ & $\mathrm{x}$ & $\mathrm{x}$ & 39 \\
\hline Trilobita & 38 & 27 & 6 & 32 & 214 & 1 & $\mathrm{x}$ & $\mathrm{x}$ & $\mathrm{x}$ & $\mathrm{x}$ & 125 \\
\hline Crinoide & 32 & 7 & 4 & 1 & $\mathrm{x}$ & $\mathrm{x}$ & $\mathrm{x}$ & $\mathrm{x}$ & 3 & 64 & 111 \\
\hline Vertebrado & 3 & $\mathrm{x}$ & 1 & $\mathrm{x}$ & 22 & $\mathrm{x}$ & 3 & $\mathrm{x}$ & $\mathrm{x}$ & $\mathrm{x}$ & 29 \\
\hline Vegetal & 47 & 89 & $\mathrm{x}$ & 4 & 2 & $\mathrm{x}$ & $\mathrm{x}$ & $\mathrm{x}$ & $\mathrm{x}$ & $\mathrm{x}$ & 142 \\
\hline Icnofóssil & 49 & 355 & 2 & 11 & 1 & $\mathrm{x}$ & $\mathrm{x}$ & 19 & $\mathrm{x}$ & $\mathrm{x}$ & 437 \\
\hline Total & 665 & 594 & 173 & 134 & 80 & 1 & 63 & 19 & 73 & 69 & 1.883 \\
\hline
\end{tabular}




\section{PATRIMÔNIO GEOLÓGICO EX SITU DA FORMAÇÃO PIMENTEIRA NA LITERATURA CIENTÍFICA}

Os trabalhos feitos sobre qualquer objeto de estudo constituem um dos principais meios de documentar sua história, sendo possível, mediante eles, reconstituir muito dos contextos histórico e científico que permearam o seu desenvolvimento. Sobre a Formação Pimenteira puderam ser elencados ao menos 54 trabalhos, dentre artigos, monografias, dissertações e teses que abordaram diferentes aspectos de seus sedimentos:

Análise geológica e listagens faunísticas: Caster (1948), Kegel (1953), Ford (1965), Suárez-Riglos (1967), Melo (1985), Melo (1988), Silva (2001), Souza (2007), Ponciano \& Della Fávera (2009), Cruz (2010), Ponciano et al. (2012 a,b), Ponciano (2013), Santos (2015).

Braquiópodes: Fonseca e Melo (1987), Fonseca (2001), Fonseca (2004), Gama Jr. (2008), Fonseca \& Ponciano (2011), Queiroz et al. (2013), Rezende et al. (2019a,b).

Biválvios: Machado (1990), Machado (1999).

Trilobitas: Castro (1968), Caldas et al. (1987), Carvalho (1995), Carvalho et al. (1997), Carvalho \& Ponciano (2015).

\section{RECONSTRUÇÕES HISTÓRICO-CIENTÍFICAS ENTRE COLEÇÕES PALEONTOLÓGICAS E A FORMAÇÃO PIMENTEIRA}

Apesar da importância das coleções para o "fazer científico", o modelo atual de produção de conhecimento tem se focado cada vez menos no estudo do material contido em instituições científicas, tornando as coleções um fator secundário nesse processo, com o papel de apenas salvaguardar seu conteúdo. Esta visão tem um efeito direto nos esforços de manutenção de instalações e de equipes voltadas às coleções, que vem sofrendo cada vez mais riscos à sua integridade enquanto fonte de informações essenciais, muitas vezes não mais disponíveis no ambiente (Landim
Gastropodes: Santos et al. (2014).

Conularídeos: Fernandes (1985), Siviero (2002).

Crinoides: Scheffler (2010), Scheffler et al. (2010), Scheffler et al. (2011).

Tentaculitoideos: Comniskey et al. (2015).

"Peixes": Janvier \& Melo (1992), Maisey \& Melo (2005), Figueroa (2016), Figueroa \& Machado (2016, 2018).

Icnofósseis: Kegel (1961), Kegel (1966), Fernandes et al. (2002), Agostinho et al. (2004), Fernandes \& Fonseca (2005), Agostinho et al. (2012), Fernandes et al. (2012), Silva et al. (2012).

Enfoque patrimonial: Souza (2006), Ponciano (2013), Kunzler et al. (2014), Santos (2015).

Enfoque didático: Ponciano (2015), Silva (2015).

Nestes trabalhos pôde ser observada maior riqueza de detalhes sobre diferentes aspectos da Formação Pimenteira, principalmente em estudos de caracterização geológica. Os estudos paleobiológicos, por sua vez, apresentam caracterização heterogênea, com alguns grupos taxonômicos se destacando por estudos mais completos e outros em estágio inicial de pesquisa.

2018). As coleções paleontológicas não são exceção, sofrendo muitas vezes com falta de espaço e acondicionamento adequado para cada tipo de estrutura geológica. Um exemplo trágico da situação destas instituições de pesquisa como um todo foi o recente incêndio ocorrido no Museu Nacional/UFRJ. Apesar dos esforços dos pesquisadores e sociedade em geral, estima-se que diversos materiais raros, inclusive fósseis, se perderam de forma definitiva.

As coleções estudadas estão apresentadas por meio de um breve histórico de origem e suas interconexões com históricos de excursões de campo, pesquisadores e produção científica que, entrelaçados, 
formam o Patrimônio ex situ da Formação Pimenteira. Cada coleção contribui para a formação deste patrimônio a sua própria maneira, sendo necessários estudos mais aprofundados voltados a cada uma para que se compreendam todas as suas diversificadas facetas.

\subsection{Coleção do Cincinnati Museum Center}

O acervo de fósseis da Universidade de Cincinnati foi iniciado em 1907 e incorporado quase um século depois, em 1998, ao Geier Collections \& Research Center, instalação parte do Cincinnati Museum Center (Figura 1). Hoje, o acervo contém mais de 90 mil exemplares fósseis, dos quais ao menos 83 amostras são provenientes da Formação Pimenteira. A reunião de dados sobre esta coleção da Formação Pimenteira foi feita por bibliografia, além de consultas aos acervos digitais da instituição (https://www.cincymuseum.org/invertebrate-paleontology/) e informações obtidas previamente, podendo não representar a totalidade de amostras que compõe a coleção da Formação Pimenteira inclusa no acervo.
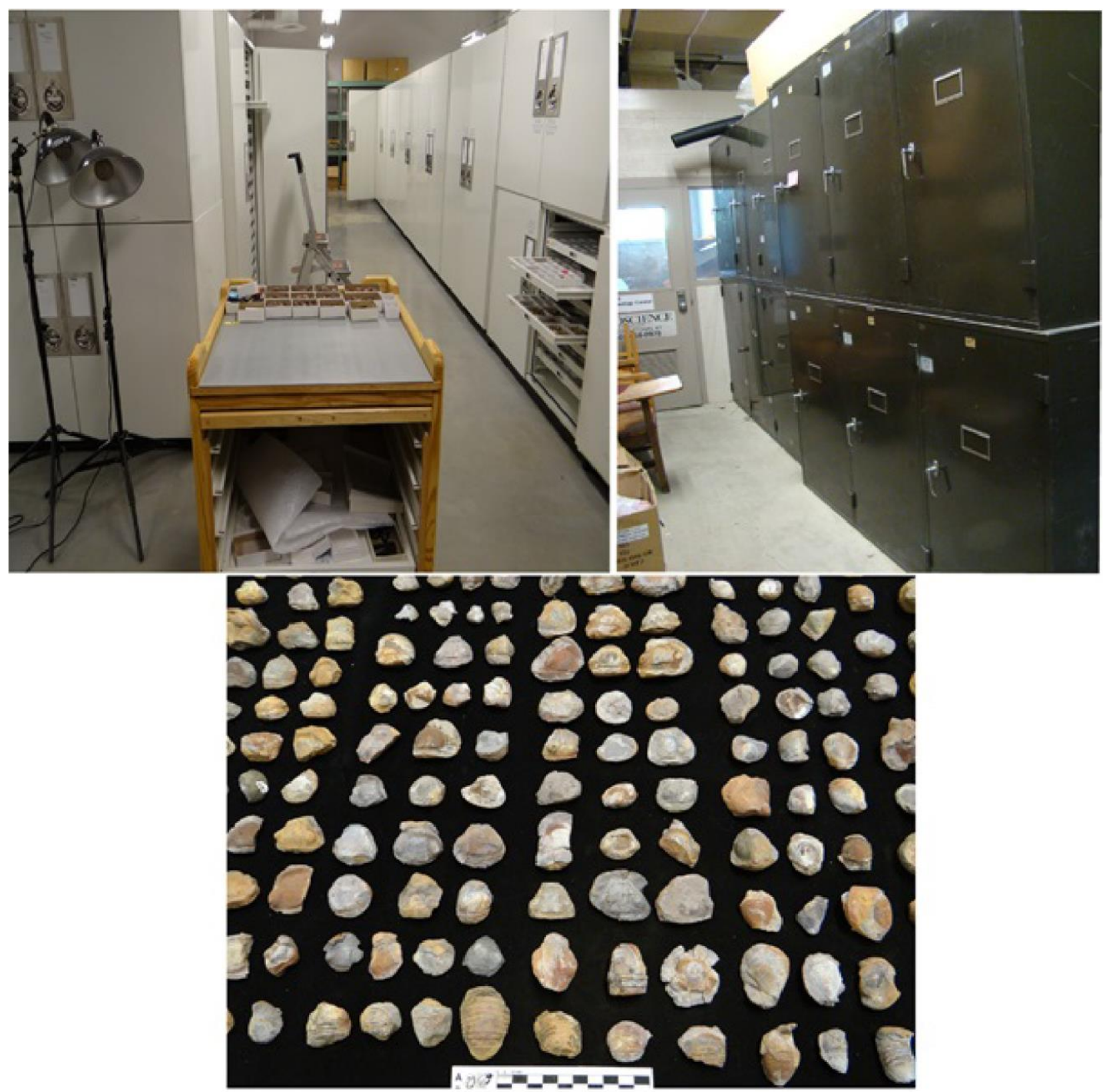

Figura 1. Geier Collections \& Research Center. Fotos: Luiza Ponciano. 
Mesmo não estando em solo brasileiro, os exemplares que foram depositados inicialmente na Universidade de Cincinnati possuem extrema importância para a história da Formação Pimenteira. Estes exemplares além de serem resultados da primeira coleta nos afloramentos desta formação, também serviram de base para a primeira identificação da idade Devoniana de suas rochas, realizada por Caster (1948). Alguns destes exemplares também foram os primeiros da Formação Pimenteira a serem descritos e ilustrados nas dissertações de Ford (1965) e Suárez-Riglos (1967).

Contudo, a importância do acervo da Formação Pimenteira contida no Cincinnati Museum Center não se resume ao período inicial de coletas na formação. Seus exemplares ainda hoje servem de base para novos estudos, o que exemplifica a relevância

\subsection{Coleção do Museu Nacional/UFRJ}

O incêndio ocorrido nas instalações do Museu Nacional consternou toda a comunidade científica e população geral, tanto dentro como fora do Brasil. Considerado um dos principais museus da América do Sul, a perda de seu acervo (Figura 2) representa um momento crítico para a ciência como um todo, motivo pelo qual o intenso trabalho de resgate por parte de seus pesquisadores e parceiros é de extrema relevância. Para além disso, tamanha tragédia representa um golpe à história do país, com perdas de valores das coleções paleontológicas (e científicas em geral) para a continuidade das pesquisas. As espécies de vertebrados fósseis descritas recentemente para a Formação Pimenteira são exemplo dessa importância. Exemplares estudados pelos pesquisadores Rodrigo Figueroa e Deusana Machado em Figueroa \& Machado $(2016,2018)$ constituem um dos estudos mais recentes sobre a Formação Pimenteira, que resultaram na revalidação de Ctenacanthus kegeli Ford, (1965) (CMC VP8341), espécie descrita originalmente na dissertação do pesquisador David Ford. Figueroa \& Machado (2016) também assinalaram a presença na Formação Pimenteira de um placodermi da família Groelandaspididae? (CMC VP5328, VP5330, VP5342, VP5344) e acantodios da ordem Climatiiformes Berg, 1940 (CMC VP5326 e VP5329).

monetários inestimáveis e insubstituíveis, representando não apenas grandes perdas no campo da pesquisa científica, mas também de enorme parte das heranças culturais brasileiras (National Geographic 2021). Uma vez que esse trabalho de resgate ainda está em andamento, buscando manter a memória desta instituição viva, as informações da Formação Pimenteira obtidas na coleção paleontológica do Museu Nacional são aqui apresentadas como ainda existentes. 

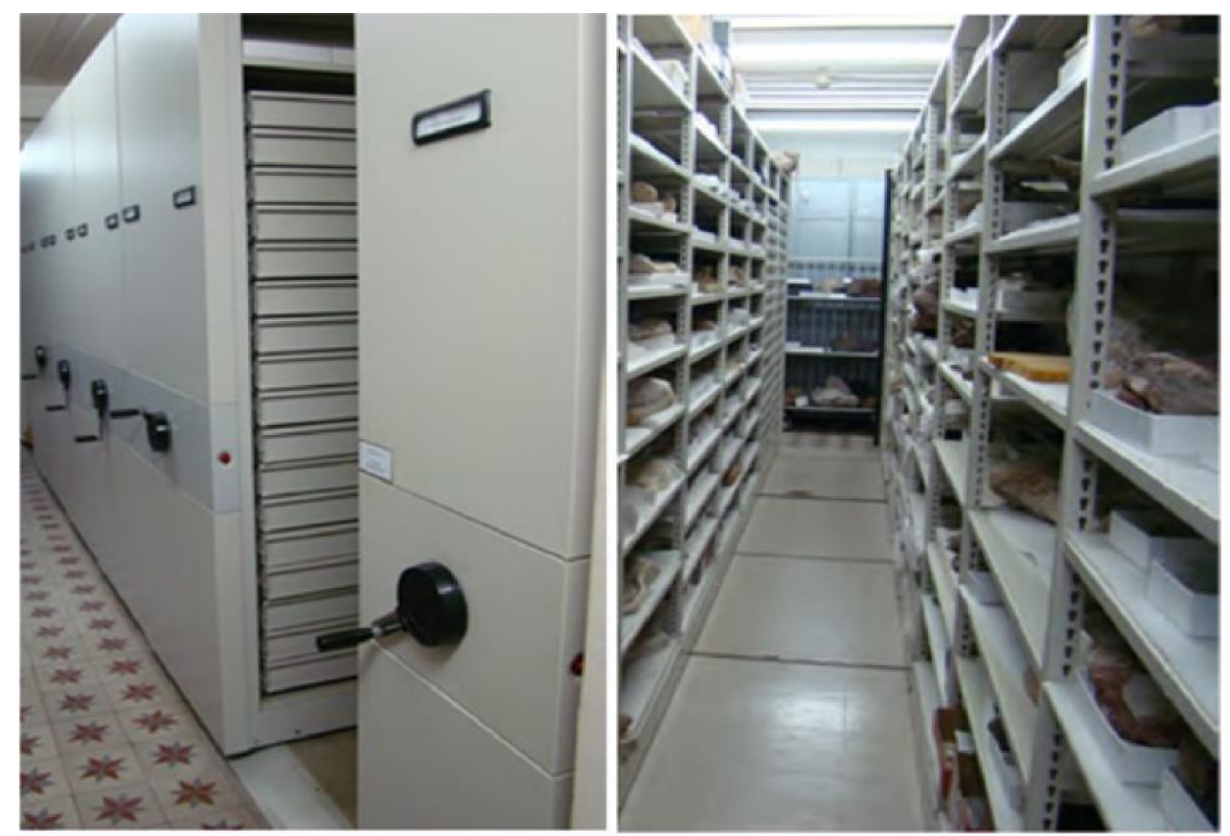

Figura 2. A. Coleção de Paleontologia do Museu Nacional. B. Fósseis da coleção de Paleontologia do Museu Nacional. Fotos: Luiza Ponciano.

O museu foi criado em 1818 por D. João VI com o intuito de promover o avanço cultural e acadêmico do país, num contexto de transição entre o Brasil colônia e o reino recém-criado em 1815 (Fernandes et al. 2006). Chamado inicialmente de Museu Real, a criação de seu acervo se deu pela incorporação da antiga Casa dos Pássaros (1779-1790) e coleções pertencentes à família real (Sily 2008). Com a independência em 1822, o museu passou a ser chamado Museu Imperial e, por fim, com a proclamação da República em 1889 passou ao nome atual de Museu Nacional.

O museu foi a primeira instituição realmente voltada para a pesquisa científica no país, sendo sua criação um marco para o desenvolvimento de uma cultura científica brasileira. Suas instalações guardam a maior parte do material coletado durante as Comissões Geológicas do Império, ocorridas de 1875 ao final do século XIX, que foram responsáveis por grandiosos avanços em todas as áreas das ciências naturalistas no Brasil (Fernandes et al. 2007). Hoje, seu acervo fossilífero possui mais de $60 \mathrm{mil}$ exemplares catalogados, dos quais os paleoinvertebrados somam ao menos $45 \mathrm{mil}$, sendo 135 amostras provenientes da Formação Pimenteira (Pássaro et al. 2014).

A coleção de fósseis da Formação Pimenteira salvaguardada no Museu Nacional teve seu desenvolvimento relacionado principalmente a excursões de campo efetuadas na década de 1980 e representa um exemplo do quanto um acervo é reflexo não só do momento histórico, mas também dos pesquisadores que contribuem para sua construção.

A maioria dos fósseis desta coleção são exemplares de braquiópodes estudados pela pesquisadora Vera Fonseca e foram importantes para os avanços nos estudos faunísticos da Formação Pimenteira. Em especial pelas descrições e registros de ocorrências de Tropidoleptus carinatus Conrad, 1839 (MN 6377-I a 6402-I) feito por Fonseca \& Melo (1987), Montsenetes cf. M. boliviensis Rachebouef, 1992 (MN 6421-I) e Pleurochonetes comstocki (Rathbun, 1874) (MN 7484-I, 7485-I, 7486-I, 7472-I, 7478-I, 7485-Ic, 7481-la e 7466-I) feitos por Fonseca (2001, 2004).

Mais recentemente, foram também tombados exemplares de crinoides coletados na Formação Pimenteira e estudados pelo pesquisador Sandro Scheffler, atual 
responsável pela coleção de paleoinvertebrados do Museu Nacional. Tais exemplares são importantes para a formação por constituírem os fósseis-tipo de Monstrocrinus incognitus Scheffler et al. 2011 (MN 8277-I), além de representarem a retomada dos estudos taxonômicos dos afloramentos da Formação Pimenteira na borda oeste da Bacia do Parnaíba.

Apesar de o acervo conter apenas dois exemplares de icnofósseis provenientes da Formação Pimenteira, estes também se mostram relevantes. A amostra 5339-1 contém dois exemplares coletados e estudados inicialmente pelo pesquisador Ignácio Brito, sendo designados como Asteriacites isp. por Brito (1977). Posteriormente, este material foi reestudado pelos pesquisadores Antonio Carlos Fernandes e Vera Fonseca, resultando na confirmação da ocorrência de Asteriacites stelliforme Miller \& Dyer, 1878 nos sedimentos na Formação Pimenteira por Fernandes e Fonseca (2005).

Entre os anos de 2011 e 2012, a coleção da Formação Pimenteira também contou com considerado acréscimo, sendo grande parte do material proveniente do Membro Passagem. Este material possui grande importância para o histórico da Formação Pimenteira, servindo de base para a caracterização de parte deste membro como topo da Formação Pimenteira (uma proposta discutida ao longo dos anos) através de estudos tafonômicos realizados por Ponciano (2013).

\subsection{Coleção do Museu de Ciências da Terra/CPRM}

A coleção mais antiga da Formação Pimenteira em território brasileiro pertence ao acervo do Museu de Ciências da Terra (MCTer/CPRM/RJ), que hoje constitui o maior acervo do país com mais de 200 mil exemplares catalogados, dos quais 111 registros pertencem a Formação Pimenteira.
O museu foi criado apenas no final do século XX, em 1992, porém a formação de seu acervo geral acompanhou a história de estruturação dos estudos geológicos do país, iniciando em 1907 com a criação do Serviço Geológico e Mineralógico do Brasil, passando pela criação do Departamento Nacional de Produção Mineral (DNPM), em 1934, e pela criação da Companhia de Pesquisa e Recursos Naturais (CPRM) em 1969. Desde 2012, a CPRM é a responsável por gerir o Museu de Ciências da Terra (Pássaro et al. 2014).

Esta instituição tem grande importância para a história da Formação Pimenteira, com exemplares coletados ainda na década de 1950 pelo pesquisador Wilhelm Kegel, em excursões de campo focadas principalmente nos arredores das cidades de Picos, Oeiras e Valença do Piauí, PI (Fernandes et al. 2012). As coletas de Kegel (1953) resultaram em grande parte dos fósseis da formação contidos no acervo, acrescido ao longo dos anos com coletas provenientes de outros trabalhos de campo, porém sem foco específico na Formação Pimenteira. Nesta coleção se encontram o holótipo do icnofóssil Neoskolithos picosensis Kegel, 1966 (DGM 4923-I), além dos fósseis-tipo dos trilobitas Metacryphaeus kegeli Carvalho et al. (1997) (DGM 6133-I) e Metacryphaeus meloi Carvalho et al. (1997) (6822-I, 6823-I e 6824-I) coletados e descritos pela pesquisadora Maria da Glória Carvalho.

São também encontrados no acervo exemplares que foram parte do material estudado por Vera Fonseca para designar as ocorrências de Pleurochonetes comstocki (DGM 6142-I, 6165-I, 6166-I e 6168-I), Mucrospirifer pedroanus (DGM 6194-I, DGM 6150-I, MCT 6870-I) e Montsenetes boliviensis? (DGM 6192-lb, 6190-la, MCT 6866-Ia) em Fonseca (2001, 2004). 


\subsection{Coleção do Museu Americano de História Natural (EUA)}

O museu possui um dos maiores acervos paleontológicos do mundo com mais de cinco milhões de amostras catalogadas, a maioria pertencente ao acervo de paleoinvertebrados, que teve seu início com a aquisição pelo museu da James Hall Collection ainda em 1875

(http://research.amnh.org/paleontology/sear ch.php) .

Neste museu foi encontrado apenas um exemplar de trilobita coletado na Formação Pimenteira, sendo este espécime um dos parátipos de Metacryphaeus meloi Carvalho et al. (1997) (AMNH 45352). Esta instituição é citada apenas pela referida publicação e, apesar do museu possuir páginas de acesso online (inclusive uma focada especialmente em trilobitas), o acesso ao seu acervo paleontológico por meio digital não resultou em novos números de tombo para a Formação Pimenteira. Por outro lado, o acervo digital disponibiliza alguns exemplares oriundos do Devoniano do estado do Paraná, além do Devoniano da Bolívia, sendo de grande interesse para estudos paleobiogeográficos na América do Sul.

\subsection{Coleção do Instituto de Geociências/UFRJ}

A formação deste acervo começou a partir da coleção mineralógica trazida por Dom João VI, que foi incorporada ainda em 1810 ao Gabinete Mineralógico da Academia Real Militar. Com a independência do Brasil em 1822, a academia foi renomeada para Academia Imperial Militar. Em 1858, com desmembramento da academia, a coleção mineralógica passou a integrar a Escola Central, transformada em Escola Politécnica do Rio de Janeiro em 1874. Já em 1937, esta escola passou a ser chamada Escola Nacional de Engenharia e foi incorporada à recémorganizada Universidade do Brasil. Por fim, em 1967 a instituição foi renomeada para Universidade Federal do Rio de Janeiro e reorganizada, dentre outros, com a criação do
Instituto de Geociências, atual detentor da coleção mineralógica e de todo o material geológico coletado ao longo de todas estas mudanças. Hoje o acervo possui 15.300 registros (Carvalho et al. 2019), dos quais 567 são provenientes da Formação Pimenteira, portanto salvaguardando a maior coleção da formação dentre os acervos analisados (https://acervo-demacrofosseis7.webnode.com/inventario/).

Com a análise das informações de coleta, foi possível observar que a coleção da Formação Pimenteira neste acervo foi desenvolvida através de trabalhos de campo ocorridos ao longo dos anos de 1960, 1970 e 1980 e, principalmente, de trabalhos de campo periódicos realizados pelos professores e alunos do curso de geologia na região da Formação Pimenteira, tendo alguns dos exemplares coletados mais recentemente dentre as coleções analisadas. Este processo de construção foi determinante para sua composição mais abrangente dos grupos da Formação Pimenteira, onde se encontram, por exemplo, a maior quantidade de restos vegetais e icnofósseis.

\subsection{Coleções "Fósseis Paleozoicos da UNIRIO" e "Fósseis Fanerozoicos da UNIRIO"}

Foi iniciada em 1999 pelo Laboratório de Estudos de Comunidades Paleozoicas com foco nas principais bacias Paleozoicas brasileiras, Paraná, Amazonas e Parnaíba. Os exemplares da Formação Pimenteira contidos nesta coleção são provenientes de trabalhos de campo realizados nos anos de 1999, 2005, 2007, 2008, 2009, 2011 e 2012 (Ponciano 2013).

A coleção possui atualmente 1617 exemplares catalogados, dos quais 527 pertencentes a Formação Pimenteira. Apesar da quantidade um pouco menor de números de tombo em relação à coleção do IGEO, esta coleção apresenta a maior diversidade taxonômica, constituindo o melhor retrato da Formação Pimenteira dentre as coleções analisadas. Nesta coleção são encontradas a 
maioria das espécies de gastrópodes, tentaculitoideos e restos de vertebrados, sendo estes também os grupos com contribuições de estudos mais recentes.

Os gastrópodes da coleção do LECP constituem um dos avanços mais recentes nos estudos taxonômicos da Formação Pimenteira, tendo sido estudados pelo pesquisador Rafael Santos, resultando nas ocorrências das espécies Bucanella aff. dereimsi Knod, 1908 (LECP 33-GP, 34-GP, 37GP, 38-GP, 40-GP, 41-GP, 42-GP, 52-GP), Bucanella cf. B laticarinata Knod, 1908 (LECP 32-GP, 33-GP, 35-GP, 39-GP, 46-GP, 51-GP e CMC IP37752, IP38462), Bucanella aff. quadrilobata Salter, 1856 (LECP 30-GP, 31-GP) e na confirmação de Plectonotus derbyi Clarke, 1899 (LECP 06-GP, 07-GP, 09-GP, 10GP, 24-GP, 27-GP, 29-GP, 45-GP, 49-GP, 50GP) (comunicação oral de Rafael Sant'Anna Santos).

Já os tentaculitoideos da Formação Pimenteira presentes no acervo do LECP foram estudados pela pesquisadora Jeanninny Comniskey, como parte de um estudo abrangente sobre os tentaculitoideos das bacias do Parnaíba e Amazonas. Destes estudos resultaram as confirmações de ocorrência das espécies Tentaculites eldredgianus Hartt \& Rathbun, 1875 (LECP 41TEN, 55-TEN), Tentaculites oseryi Clarke, 1899 (LECP 54-TEN, 58-TEN, 59-TEN, 101-TEN) e Styliolina clavulus Barrande, 1852 (LECP 42TEN) por Comniskey et al. (2015).

O material de vertebrados fósseis da Formação Pimenteira contido no LECP também fez parte dos estudos de Figueroa \& Machado (2016), que resultou nas descrições de ocorrência de espinhos do gênero cf. Antarctilamna Young, 1982 (LECP 01-Px) e da ordem Climatiiformes Berg, 1940 (LECP 10$\mathrm{Px})$.

Todas as coleções visitadas durante a pesquisa estavam em processo de reorganização e melhoria nos sistemas de tombamento e catalogação do material. Contudo, em 2011 o acervo do LECP foi um dos primeiros a ter a documentação fotográfica e audiovisual tanto de seus fósseis, quanto dos processos relacionados à sua coleta, acondicionamento e estudo (Novaes 2018). O reconhecimento da importância dos outros tipos de materiais ex situ garante que os agentes envolvidos e o contexto histórico dos fósseis não se percam. Ao figurar os fósseis e os afloramentos estudados, também está garantida uma melhor manutenção das informações primárias, muitas vezes perdidas no processo de tombamento e ao longo dos anos de salvaguarda (Ponciano et al. 2011).

Já a coleção "Fósseis Fanerozoicos da UNIRIO" foi criada em 2019 pelo Laboratório de Tafonomia e Paleoecologia Aplicadas, a partir da coleção de fósseis estrangeiros com foco nas principais bacias paleozoicas brasileiras e em afloramentos de países como Marrocos, Espanha e Estados Unidos, além de espécimes coletados em expedição à Antártida em parceria com o Museu Nacional do Rio de Janeiro. Com relação ao material brasileiro, os exemplares da Formação Pimenteira (membros Picos e Passagem) e da Formação Longá contidos nesta coleção são provenientes de trabalhos de campo realizados nos anos de 2009 e 2011 (Ponciano 2013), e o material proveniente da Formação Ponta Grossa (Bacia do Paraná) foram coletados em excursão organizada pelo IV Simpósio Brasileiro de Patrimônio Geológico em Ponta Grossa, Paraná, no ano de 2017.

Apesar de os acervos contidos nas universidades UFPE e UFT não terem sido visitados, assim como os acervos do Museu Emílio Goeldi (MPEG) e Museu de Geociências da UnB, também foi possível constatar a relevância histórico patrimonial destes para a Formação Pimenteira.

\subsection{Coleção do Museu Paraense Emílio Goeldi (MPEG)}

O museu foi criado em 1866, tendo sua coleção paleontológica iniciada em 1896. Foi uma das primeiras instituições a promover o estudo das ciências naturais na região amazônica, que teve Karl Friedrick Katzer como um de seus principais pesquisadores do 
período. Hoje seu acervo paleontológico conta com cerca de 6 mil exemplares catalogados, dentre os quais 56 pertencentes a Formação Pimenteira (https://www.museugoeldi.br/assuntos/colecoes/fosseis-mineraisrochas). Os dados bibliográficos sugerem que a coleção da Formação Pimenteira remete principalmente a excursões de campo ocorridas entre as décadas de 1980 e 1990.

Através da literatura observou-se que, nesta coleção se encontram alguns braquiópodes, restos de vertebrados e grande quantidade de biválvios, estes últimos estudados pela pesquisadora Deusana Machado. Seus estudos resultaram nas descrições de ocorrência de Nuculites cf. N. oblongatus (MPEG 1320-I, 1353-I, 1390-I), Cucullella triquetra (Conrad, 1841) (MPEG 1309-I, 1321I, 1356-I, 1359-I, 1362-I, 1366-I, 1375-I, 1389I, 1391-I, 1403-I), Grammysioidea lundi Clarke, 1899 (MPEG 1333-I, 1335-I, 1337-I, 1341-I, 1348-I, 1350-I, 1351-I, 1352-I, 1355-I, 1356-I, 1357-I, 1358-I, 1361-I, 1364-I, 1367-I, 1370-I, 1373-I, 1376-I, 1377-I, 1379-I, 1380-I, 1382-I, 1385-I, 1387-I, 1389-I, 1394-I, 1397-I, 1398-I, 1399-I) e Spathella pimentana Hartt e Rathbun, 1875 (MPEG 1360-I, 1370-I, 1388-I, 1393-I, 1399-I, 1400-I) por Machado (1999).

A coleção também possui grande importância para o estudo dos vertebrados fósseis da Formação Pimenteira, com exemplares estudados pelos pesquisadores John Maisey e José Henrique de Melo. Estes estudos resultaram, dentre outros avanços, na descrição do primeiro dente bicúspide (MPEG 220-v-b) datado do Devoniano brasileiro por Maisey \& Melo (2005). Segundo os autores, o dente seria também o segundo reportado para o Devoniano da América do Sul e poderia pertencer aos gêneros Leonodus Mader, 1986 ou Antarctilamna Young, 1982.

\subsection{Coleção do Museu de Geociências da UnB}

O museu teve início em 1965 com a criação do curso de Geologia na UnB. Seu acervo vem sendo construído ao longo dos anos através de trabalhos de campo realizados pelos professores e alunos do Instituto de Geociências, além de doações de colecionadores e mineradoras, entre outros. Seu acervo conta hoje com mais de 1.000 amostras provenientes de diversas regiões brasileiras e do exterior, dentre as quais 87 são provenientes da Formação Pimenteira (http://mw.eco.br/ig/exte/museu/index.htm).

Esta coleção possui importantes exemplares de braquiópodes da Formação Pimenteira coletados na borda oeste da Bacia do Parnaíba. Este material foi estudado na dissertação do pesquisador José Gama Júnior que, além de descrever as ocorrências de espécies já conhecidas da Formação Pimenteira, também para a borda oeste, registrou a ocorrência de Montsenetes carolinae Fonseca, 2004 (243, 244, 245, 246, 247, 248, 249, 250, 251, 252, 253, 254, 255, $256,257,258,259,260,261,262,263,264$, 265, 285, 357, 358) para a Formação Pimenteira, originalmente descrita pela pesquisadora Vera Fonseca para as rochas da Formação Maecuru da Bacia do Amazonas.

\subsection{Coleção do Departamento de Geologia da UFPE}

A coleção geral foi iniciada no contexto de criação do Departamento de Geologia, em 1967, e também documentou importantes avanços nos estudos paleontológicos no Norte e Nordeste brasileiro, tendo passado por ela pesquisadores como Karl Beurlen e Geraldo Muniz. O crescimento da coleção da Formação Pimenteira nessa instituição também é relacionado às coletas ocorridas ao longo dos anos pelos professores e alunos do curso de Geologia. Hoje a coleção reúne pelo menos 10.000 exemplares catalogados, dos quais ao menos 184 amostras são pertencentes às rochas da Formação Pimenteira

(https://www3.ufpe.br/geologia/paginas/labo ratorios/paleoLab/Colecao-Macro.html).

Apesar de terem sido encontrados poucos exemplares da Formação Pimenteira através da literatura, a coleção tem grande 
importância principalmente para o estudo dos icnofósseis da formação. Nela estão salvaguardados os materiais estudados pela pesquisadora Sonia Agostinho, que resultaram na designação das icnoespécies Bifungites piauienses Agostinho et al. 2004 (5654 - holótipo, 5642, 5647, 5664, 5665) e Bifungites munizi Agostinho et al. 2004 (DGCTG 5689 - holótipo, 5690, 5691), além do material estudado pelo pesquisador Geraldo Muniz, que resultou na designação da icnoespécie Merostomichnites piauienses Muniz, 1988 (DG-CTG 3249 - holótipo, 3250, 3251).

\subsection{Coleção do Laboratório de Paleobiologia da UFT}

Não foram encontrados dados sobre o início desta coleção e a quantidade de material salvaguardado, porém foi possível constatar a presença de pelo menos 54 exemplares provenientes da Formação Pimenteira.

Esta coleção possui grande importância para a Formação Pimenteira, salvaguardando a maioria dos exemplares de crinoides da formação, material este também estudado pelo pesquisador Sandro Scheffler, que o utilizou como base para a descrição de Exaesiodiscus dimerocrinosus Scheffler et al. 2011 (UFT 153, 240, 241, 243, 298 - síntipos, $178,187,336,346,347,348,349,350,351$, $352,353,354,355,356,392,393,395,396$, $397,398,399,401)$.

A coleção é também importante por remeter a retomada de estudos da Formação Pimenteira na borda oeste da Bacia do Parnaíba depois de muitos anos com enfoque das pesquisas no Piauí. Como resultado, novos estudos vêm sendo realizados, com foco principalmente nos braquiópodes, mais recentemente estudados pelo pesquisador José Gama Júnior. Com estes estudos, foram descritas novas ocorrências de espécies para a borda oeste, a exemplo de Australospirifer iheringi (Kayser 1900) (UFT 732c e 790) por Queiroz et al. (2013).

\section{CONCLUSÕES}

Através do conjunto das coleções paleontológicas estudadas foram encontrados de 1.639 números de tombo, totalizando 1.340 reunidos das instituições visitadas e 299 reunidos através de bibliografia. Foram encontrados 1.871 espécimes pertencentes a 12 grupos taxonômicos, braquiópodes (Filo Brachiopoda), biválvios (Classe Bivalvia), gastrópodes e belerofontídeos (Classe Gastropoda), tentaculitoideos (Classe Tentaculitoidea), trilobitas (Classe Trilobita), conularídeos (Família Conulariidae), crinoides (Classe Crinoidea), vertebrados marinhos (Classes Placodermi, Chondrichthyes e Acanthodii), restos de vegetais terrestres (Filos Lycopodiophyta e Pteridophyta), e uma grande quantidade de icnofósseis. Também foram elencados 54 trabalhos que detalham as informações da Formação Pimenteira em diferentes prismas.

Observando todo o material ex situ reunido, foi possível vislumbrar as interrelações entre os diversos agentes - coleções, pesquisadores, publicações e contextualização histórica em si - que constituem o patrimônio geológico ex situ da Formação Pimenteira, demonstrando as possibilidades de estudo oferecidas por este tipo de patrimônio que possam visar à conservação da geodiversidade em diferentes aspectos.

\section{NOTA DEDICATÓRIA}

Mais uma vez explicitamos que, apesar do incêndio que destruiu as instalações do Museu Nacional, os autores optaram por manter todas as referências ao material de sua coleção paleontológica no presente, uma vez que o processo de salvamento não foi finalizado e que, por isso, o material não pode ser dado como perdido de forma definitiva. Além disso, acreditamos que a instituição Museu Nacional transcende suas barreiras físicas e, assim, o "Museu Nacional VIVE". 


\section{AGRADECIMENTOS}

J.M.P.R gostaria de agradecer ao Conselho de Aperfeiçoamento de Pessoal de Nível Superior (CAPES) [88887.484101/2020-00], e à Fundação de Amparo à Pesquisa do Estado do Rio de Janeiro (FAPERJ) [E26/201.664/2021] pelas bolsas que subsidiaram a pesquisa

\section{REFERÊNCIAS}

AGOSTINHO S., VIANA M.S.S., FERNANDES A.C.S. 2004. Duas novas icnoespécies de Bifungites Desio, 1940 na Formação Pimenteira, Devoniano da Bacia do Parnaíba, Brasil. Arquivos do Museu Nacional. 62 (4): 519- 530.

AGOSTINHO S., BATISTA Z.V., BARROS C.L., GOMES C.R., SANTOS C.A. 2012. Icnofósseis devonianos da Formação Pimenteira, estado do Piauí, e suas implicações paleoambientais e paleogeográficas. Estudos Geológicos. 22 (1): 117-120.

BRILHA J. 2005. Património Geológico e Geoconservação: A Conservação da Natureza em sua vertente geológica. Braga: Palimage Editores, Braga. 190p.

BRILHA J. 2016. Inventory and Quantitative Assessment of Geosites and Geodiversity Sites: a Review. Geoheritage. 8 (2): 119-134.

BRITO I.M. 1977. Ocorrência de bióglifos no Devoniano Inferior do Município de Tocantínia, Goiás. Anais da Academia Brasileira de Ciências. 49 (3): 461-464.

CALDAS E.B., FLORÊNCIO C.P., LIMA FILHO F.P. 1987. Nova ocorrência de Metacryphaeus cf. australis no Devoniano médio da Bacia do Parnaíba. In: X Congresso Brasileiro de Paleontologia, Anais, Rio de Janeiro: SBP. 539544.

CARVALHO M.G.P. 1995. Trilobitas do Devoniano da Bacia do Parnaíba. Tese de Doutorado. Programa de Pós-Graduação em Geologia, Departamento de Geologia, Universidade Federal do Rio de Janeiro, 132p.
CARVALHO M.G.P., EDGECOMBE G.D., LIEBERMAN B.S. 1997. Devonian calmoniid trilobites from the Parnaíba Basin, Piauí State, Brazil. American Museum Novitates. 3.192:111.

CARVALHO M.G.P., PONCIANO L.C.M.O. 2015. The devonian trilobites of Brazil: A summary. Journal of South American Earth Sciences. 64: 217-228.

CARVALHO I.S., FIGUEIREDO F.A.S., BOSIO P.S. \& RIBEIRO R.P. 2019. Memória da Paleontologia Brasileira: Coleção UFRJDepartamento de Geologia. In: Livro de resumos Paleo Fall meeting, 27-27p.

CASTER K.E. 1948. Excursão Geológica ao Estado do Piauí. Mineração e Metalurgia. 12 (72): 271- 274.

CASTER K.E., MENDES J.C. 1952. Comparação geológica entre América do Sul e África do Sul. Publicação da Divisão de Geologia e Mineralogia do DNPM. Rio de Janeiro.

CASTRO J.S. 1968. Trilobitas da Formação Pimenteiras, Devoniano do Estado do Piauí. Anais da Academia Brasileira de Ciências. 40 (4): 481-489.

CASTRO A.R.F.S. 2006. O conteúdo fossilífero da Formação Pimenteira como parte do Patrimônio Geológico brasileiro. Monografia em Museologia, Bacharelado em Museologia, Escola e Museologia, Universidade Federal do Estado do Rio de Janeiro.

CASTRO A.R.S.F., MANSUR K.L., CARVALHO I.S. 2018. Reflexões sobre as relações entre geodiversidade e patrimônio: um estudo de caso.Terr@Plural. 12 (3): 383-403.

CMC - Cincinnati Museum Center. Invertebrate Paleontology. https://www.cincymuseum.org/invertebratepaleontology/. Acessado em 02 de Agosto de 2019.

COMNISKEY J.C., GHILARD R.P., BOSETTI E.P. 2015. Conhecimento atual sobre os tentaculitoideos devonianos das bacias do Amazonas e Parnaíba, Brasil, depositados em instituições brasileiras. Boletim do Museu 
Paraense Emílio Goeldi - Ciências Naturais.10 (1): 49-61.

CRUZ, C. E. S. Excursão de Campo: Borda Oeste da Bacia do Parnaíba. Relatório PETROBRAS/CENPES/PDEXP/GSEP. p. 44, mai, 2010.

FERNANDES A.C.S. 1985. Cnidários fósseis brasileiros: histórico das pesquisas e considerações sobre seu desenvolvimento. Boletim do Departamento Nacional de Produção Mineral - Série Geologia. 27: 201204.

FERNANDES A.C.S., BORGHI L., CARVALHO I.S., ABREU C.J. 2002. Guia dos Icnofósseis de Invertebrados do Brasil. Interciência, Rio de Janeiro, 258p.

FERNANDES A.C.S., FONSECA V.M.M. 2005. A contribuição de Ignácio Aureliano Machado Brito à icnologia brasileira. Arquivos do Museu Nacional. 63 (3): 619-624.

FERNANDES, A C. S.; FONSECA, V. M. M.; VIEIRA, P. M.; MARINO, L. M. Os fósseis estrangeiros da coleção de paleoinvertebrados do Museu Nacional. Publicações Avulsas do Museu Nacional, Rio de Janeiro: UFRJ, n. 108, p. 1-36, 2006.

FERNANDES A.C.S., FONSECA V.M.M., HENRIQUES D.D.R. 2007. Histórico da paleontologia no Museu Nacional. Anuário do Instituto de Geociências. 30: 188-190.

FERNANDES A.C.S., FONSECA V.M.M., PONCIANO L.C.M.O. 2012. Icnofósseis da Bacia do Parnaíba: As contribuições de Wilhelm Kegel. Revista Brasileira de Paleontologia. 15 (2): 153-163.

FIGUEROA, R.T. 2016. Paleoictiofauna do Paleozooico das bacias do Amazonas e Parnaíba, Brasil. Monografia em Ciências Biológicas, Bacharelado em Ciências Biológicas, Departamento de Ciências Naturais, Universidade Federal do Estado do Rio de Janeiro, 74p.

FIGUEROA R.T., MACHADO D.M.C. 2016. Paleoictiofauna da Formação Pimenteira (Devoniano), Bacia do Parnaíba, PI, Brasil.
Revista Brasileira de Paleontologia.19 (3): 491-504.

FIGUEROA R.T., MACHADO, D.M.C. 2018. The Paleozoic ichthyofauna of the Amazonas and Parnaíba basins, Brazil. Journal of South American Earth Sciences. 82: 122-132.

FONSECA V.M.M., Melo J.H.G. 1987. Ocorrência de Tropiloleptos carinatus (Conrad) (Brachiopoda, Orthida) na Formação Pimenteira e sua importância paleobiogeográfica. In: X Congresso Brasileiro de Paleontologia. Anais, Rio de Janeiro: SBP. 505-537.

FONSECA, Vera Maria Medina da. Brachiopoda (Stropheodontoidea, Chonetoidea e Delthyriridoidea) do Devoniano Médio das Bacias do Amazonas e Parnaíba. Tese de Doutorado. Programa de Pós-Graduação em Geologia, Departamento de Geologia, Universidade Federal do Rio de Janeiro, 195p.

FONSECA V.M.M. 2004. Chonetoidea (Brachiopoda) do Devoniano Médio das Bacias do Amazonas e Parnaíba, Brasil. Arquivos do Museu Nacional. 62 (2):193-215.

FONSECA V.M.M., PONCIANO L.C.M.O. 2011. Braquiópodes do Devoniano médio das Bacias do Amazonas e Parnaíba. In: CARVALHO I.S., SRIVASTAVA N.K. (eds) Paleontologia: Cenários de Vida. 4. ed. Rio de Janeiro: Interciência, 127-148p.

FORD D. 1965. Devonian fauna in the concretionary Picos Member, Pimenteira Formation (Lower Devonian) Piauí, Brazil. Dissertação de Mestrado, University of Cincinnati, 95p.

GAMA JR. J.M. 2008. Braquiópodes da Formação Pimenteira (Devoniano médio/superior), na região sudoeste da Bacia do Parnaíba, Município de Palmas, estado do Tocantins, Brasil. Dissertação de Mestrado, Programa de Pós-Graduação em Geologia Regional, Universidade de Brasília, 64p.

JANVIER P., MELO J.H.G. 1992. New acanthodian and chondrichthyan remains from the Lower and Middle Devonian of 
Brazil. Neues Jahrbuch fur Geologie und Paleontologie. 4: 193-206.

KEGEL W. 1953. Contribuição para o estudo do Devoniano da Bacia do Parnaíba. Boletim da Divisão de Geologia e Mineralogia. 141: 148.

KEGEL W. 1961. Rasto de um trilobita (?Homalonotus) do Devoniano Inferior do Piauí. Anais da Academia Brasileira de Ciências. 33 (2): 163-167.

KEGEL W. 1966. Rastos do Devoniano da Bacia do Parnaíba, Brasil. Boletim da Divisão de Geologia e Mineralogia. 233: 1-32.

KUNZLER J., MACHADO D.M.C., NOVAES M.G.L., PONCIANO L.C.M.O. 2014. Coleções paleontológicas como proteção do Patrimônio Científico brasileiro. In: III Seminário Internacional Cultura Material e Patrimônio da Ciência e Tecnologia, Rio de Janeiro. 1: 385-407.

KUNZLER J., MACHADO D.M.C. 2019. Fósseis e patrimônio paleontológico: um retorno ao integral. Museologia e Patrimônio. 12 (2): 6496.

LANDIM I.M. 2018. Um oceano de desconhecimento sobre a biodiversidade. Museologia \& Interdisciplinaridade. 7: 88-106.

MACHADO D.M.C. 1990. Biválvios devonianos da Bacia do Amazonas (formações Maecuru e Ererê): considerações sistemáticas e paleoautoecológicas. Dissertação de Mestrado, Programa de Pós-Graduação em Geologia, Departamento de Geologia, Universidade Federal do Rio de Janeiro, 228p.

MACHADO D.M.C. 1999. Nuculites Conrad, 1841 (Mollusca, Bivalvia): sistemática e implicações paleobiogeográficas. Tese de Doutorado, Programa de Pós-Graduação em Geociências, Universidade Federal do Rio Grande do Sul, 298p.

MACHADO D.M.C., NOVAES M.L.G., FERREIRA L.F.L., REZENDE J.M.P. 2017. Coleção científica "Fósseis Paleozoicos" - Unirio: Conservação da memória institucional e o "Fazer Paleontologia". In: Anais do IV Simpósio Brasileiro de Patrimônio Geológico e
II Encontro Luso-Brasileiro de Patrimônio Geomorfológico e Geoconservação. 118121p.

MACHADO M.M.M. RUCHKYS U.A. 2015. Essa tal geodiversidade. Revista UFMG. 22 (1-2): 182-193.

MAISEY J.G., MELO J.H.G. 2005. Some Middle Devonian (Eifelian-Givetian) fossil fish remains from the Pimenteira Formation of the Parnaíba Basin, Northeast Brazil. Arquivos do Museu Nacional. 63 (3): 495-505.

MANSUR K.L., PONCIANO L.C.M.O., CASTRO A.R.S.F., CARVALHO I.S. 2013. Conservação e restauro do Patrimônio Geológico e sua relevância para a geoconservação. Boletim Paranaense de Geociências. 70 (2013): 137155.

MEIRA S.A., MORAIS, J.O. 2016. Os conceitos de geodiversidade, patrimônio geológico e geoconservação: abordagens sobre o papel da geografia no estudo da temática. Boletim de Geografia. 34 (3): 129-147.

MELO J.H.G. 1985. A província Malvinocáfrica no Devoniano do Brasil: estado atual dos conhecimentos. Dissertação de Mestrado, Programa de Pós-Graduação em Geologia, Departamento de Geologia, Universidade Federal do Rio de Janeiro, 1357p.

MELO J.H.G. 1988. The Malvinokaffric Realm in the Devonian of Brazil. In: Devonian of the World: Proceedings of the Second Synposium on the Devonian System. Calgary: Canadian Society of Petroleum Geologists. 14(1): 669703.

MPEG - Museu Paraense Emílio Goeldi. Fósseis, Minerais e Rochas. https://www.museugoeldi.br/assuntos/colecoes/fosseis-mineraisrochas. Acessado em 02 de Agosto de 2019.

NATIONAL GEOGRAPHIC. https://www.nationalgeographicbrasil.com/m useu-nacional-do-rio-de-

janeiro/2018/09/incendio-em-museu-destroiparte-fundamental-da-historia-do . Acessado em 04 de Junho de 2021. 
NOVAES. M.L.G. 2018. Patrimônio científico nas universidades brasileiras: políticas de preservação e gestão das coleções não vinculadas a museus. Tese de Doutorado, Programa de Pós- Graduação em Museologia e Patrimônio, Escola de Museologia, Universidade Federal do Estado do Rio de Janeiro, 274p.

PALEOLAB - Laboratório de Paleontologia do Departamento de Geologia da UFPE. Coleção de Macrofósseis. Disponível em https://www3.ufpe.br/geologia/paginas/labor atorios/paleoLab/Colecao-Macro.html

Acessado em 02 de Agosto de 2019.

PÁSSARO E.M., HESSEL M.H., NETO J.A.N. 2014. Principais acervos de paleontologia do Brasil. Anuário do Instituto de Geociências. 37 (2): 48-59.

PONCIANO L.C.M.O. 2012. Fósseis devonianos da Bacia do Parnaíba. 1 ed. Florianópolis: Bookess, 1-127p.

PONCIANO L.C.M.O. 2013. Tafocenoses mesodevonianas da Bacia do Parnaíba no estado do Piauí: análise tafonômica, paleoambiental e patrimonial. Tese de Doutorado, Programa de Pós-Graduação em Geologia, Departamento de Geologia, Universidade Federal do Rio de Janeiro, 302p.

PONCIANO L.C.M.O. 2015. Tafonomia de invertebrados: o enigma das conchas. In: A paleontologia na sala de aula. 1ed. Ribeirão Preto: SBP, 273-294p.

PONCIANO L.C.M.O., DELLA FÁVERA J.C. 2009. Flood-dominated fluvio-deltaic system: a new depositional model to Cabeças Formation, Parnaíba Basin, Piauí, Brazil. Anais da Academia Brasileira de Ciências. 81:769-780.

PONCIANO L.C.M.O., FONSECA V.M.M., FERNANDES A.C.S. MACHADO D.M.C., SOUZA, A.R. 2010. Afloramento fossilífero de Oiti, Bacia do Parnaíba, PI: Registro de um mar devoniano no Nordeste do Brasil. In: Sítios Geológicos e Paleontológicos do Brasil. Serviço Geológico do Brasil - CPRM, 191-200p.

$\begin{array}{llrl}\text { PONCIANO } & \text { L.C.M.O., } & \text { CASTRO } & \text { A.R.S.F., } \\ \text { MACHADO } & \text { D.M.C., } & \text { FONSECA } & \text { V.M.M., }\end{array}$

KUNZLER, J. 2011. Patrimônio GeológicoPaleontológico in situ e ex situ: Definições, vantagens, desvantagens e estratégias de conservação In: Paleontologia: Cenários de Vida. 4. ed. Rio de Janeiro: Interciência, 853869p.

PONCIANO L.C.M.O., CASTRO A.R.S.F., FONSECA V.M.M., MACHADO D.M.C. $2012 \mathrm{a}$. Tafocenoses da Formação Pimenteira, Devoniano da Bacia do Parnaíba, Piauí: Mapeamento, Inventário e Relevância Patrimonial. Anuário do Instituto de Geociências. 35 (1): 5-27.

PONCIANO L.C.M.O., FONSECA V.M.M., MACHADO D.M.C. 2012b. Taphofacies analysis of late early Givetian fossil assemblages of the Parnaíba Basin (State of Piauí, northeast Brazil). Palaeogeography, Palaeoclimatology, Palaeoecology. 326-328: 95-108.

QUEIROZ, J. P., GAMA JR. J.M., PIRES E.F. 2013. Ocorrência de braquiópodes fósseis no entorno do Rio Balsas, Município de Santa Teresa, Estado do Tocantins, em estratos da Formação Pimenteira, Devoniano da bacia do Parnaíba. Brazilian Geographical Journal: Geosciences and Humanities research medium. 4 (1): 191-212.

REZENDE, J. M. P.; MACHADO, D. M. C.; PONCIANO, L. C. M. O. A taxonomic review of the brachiopod genus Australocoelia (Boucot \& Gill, 1956), in the Devonian of Brazil. Zootaxa. Auckland: Nova Zelândia, v. 4683, p. 515-530, 2019a.

REZENDE, J. M. P.; PONCIANO, L. C. M. O.; BRETT, C. E. Brachiopod fauna from Longá Formation (Upper Devonian), State of Piauí, NE, Brazil. Historical Biology, v. 31, p. 1-12, 2019b.

SANTOS C.M.S. 2015. Catálogo de Paleoinvertebrados da Formação Pimenteira: uma iniciativa de cunho científico, patrimonial e didático. Monografia em Ciências Biológicas, Bacharelado em Ciências Biológicas, Departamento de Ciências Naturais, Universidade Federal do Estado do Rio de Janeiro. 118p. 
SANTOS R.S., MACHADO D.M.C., PONCIANO L.C.M.O. 2014. Gastropodes e belerofontides da Formação Pimenteira (Devoniano Médio) Bacia do Parnaíba Piauí Brasil. In: XIII Jornada de Iniciação Científica da UNIRIO, Livro de Resumos, 1-2p.

SCHEFFLER, S.M. 2010. Crinoides e blastóides do Devoniano brasileiro. Tese de Doutorado, Programa de Pós-Graduação em Geologia, Departamento de Geologia, Universidade Federal do Rio de Janeiro, 354p.

SCHEFFLER S.M., SILVA C.F., FERNANDES A.C.S., FONSECA V.M.M. 2010. Crinoides da borda leste da Bacia do Parnaíba (Formação Cabeças, Devoniano Médio). Boletim do Museu Paraense Emílio Goeldi - Série Ciências Naturais. 5(2):165-173.

SCHEFFLER S.M., DIAS-DA-SILVA S., GAMA JR. J.M., FONSECA V.M.M., FERNANDES A.C.S. 2011. Middle Devonian Crinoids from the Parnaiba Basin (Pimenteira Formation, Tocantins State, Brazil). Journal of Paleontology. 85(6): 1188-1198.

SILVA C.F. 2001. Estudo dos hábitos de vida dos macrofósseis da Formação Cabeças (Devoniano) da Bacia do Parnaíba. Monografia em Ciências Biológicas, Bacharelado em Ciências Biológicas, Departamento de Ciências Naturais, Universidade Federal do Estado do Rio de Janeiro, 71p.

SILVA M.D.P. 2015. Patrimônio paleontológico do estado do Piauí: Avaliação do ensino de geociências através de questionários. Monografia em Ciências Biológicas, Bacharelado em Ciências Biológicas, Departamento de Ciências Naturais, Universidade Federal do Estado do Rio de Janeiro.

SILVA M.L.N., NASCIMENTO M.A.L. 2016. Os Valores da Geodiversidade de Acordo com os Serviços Ecossistêmicos sensu Murray Gray Aplicados a Estudos in situ na Cidade do Natal (RN). Caderno de Geografia. 26 (2): 338-354.

SILVA R.C., DOMINATO V.H., FERNANDES A.C.S. 2012. Novos registros e aspectos paleoambientais dos icnofósseis da Formação Pimenteira, Devoniano da Bacia do Parnaíba, Piauí, Brasil. Journal of Geoscience. 8 (1): 3341.

SILVA R.G.P., MANSUR K.L., CASTRO A.R.S.F. 2020. Consolidação da Geodiversidade como Patrimônio e o Valor Geológico dos Monumentos do Rio de Janeiro. Anuário do Instituto de Geociências. 43 (3): 488-497.

SILY P.R.M. 2008. Práticas educativas do Museu Nacional do Rio de Janeiro no início do século 20. In: V Congresso Brasileiro de História da Educação, Anais.

SIVIERO F.N. 2002. Revisão sistemática das conulárias brasileiras. Dissertação de Mestrado, Programa de Pós-Graduação em Geologia, Departamento de Geologia, Universidade Federal do Rio de Janeiro, 80p.

SMALL H.L. 1914. Geologia e suprimento d'agua subterranea no Piauhy e parte do Ceará. Inspectoria de Obras Contra as Seccas, $168 p$.

SOUZA, Aline Rocha de. O conteúdo fossilífero da Formação Pimenteira como parte do Patrimônio Geológico Brasileiro. Monografia em Museologia. Rio de Janeiro: UNIRIO, 2006.

SOUZA, Igor Viegas Alves Fernandes de. Faciologia orgânica de seções devonianas da Bacia do Parnaíba (Formação Pimenteira): Implicações para geração de petróleo. Dissertação em Geologia, Rio de Janeiro: UFRJ, 2007.

SUÁREZ-RIGLOS M. 1967. Some Devonian fossils from the State of Piauí, Brazil. Dissertação de Mestrado, University of Cincinnati, 122p.

UCEDA, A.C. 1996. El Património Geológico. Ideas para su proyección, conservación y utilización. In: MOPTIMA (Ministerio de obras públicas, transportes y medio ambiente). El patrimonio geológico: bases para su valoración, protección, conservación y utilización. 17-28p.

UFRF-IGEO-DG - Coleção de Macrofósseis. Inventário. 
macrofosseis7.webnode.com/inventario/

Acessado em 02 de Agosto de 2019.

UNESCO - United Nations Educational, Scientific and Cultural Organization.

Documents.

https://whc.unesco.org/archive/conventionpt.pdf . Acessado em 02 de Agosto de 2019.

VAZ P.T., REZENDE N.G.A.M., WANDERLEY FILHO J.R., TRAVASSOS W.A.S. 2007. Bacia do Parnaíba. Boletim de Geociências da Petrobrás. 15 (2): 253-263.

Submetido em 29/03/2021

Aceito em 11/08/2021 